\title{
Dynamics and Change Features of the Eco-Environment Restoration in the Worst Hit Area of a Strong Earthquake
}

\author{
Linsen Duan ${ }^{1}$, Mingshun Xiang ${ }^{1,2}$, Jin Yang ${ }^{1,2^{*}}$, Xiaohan Wei ${ }^{1}$, Chunjian Wang ${ }^{1}$ \\ ${ }^{1}$ College of Tourism and Urban-Rural Planning, Chengdu University of Technology, Chengdu 610059, China \\ 2. Research Center for Human Geography of Tibetan Plateau and Its Eastern Slope (Chengdu University of Technology), \\ Chengdu 610059, China
}

Corresponding Author Email: yangj@cdut.edu.cn

https://doi.org/10.18280/ijsdp.150604

Received: 3 March 2020

Accepted: 18 June 2020

\section{Keywords:}

eco-environment, remote sensing, change features, 2008 Sichuan Earthquake

\begin{abstract}
The 2008 Sichuan Earthquake brought severe damage and long-lasting impact to the ecoenvironment in the disaster area. To restore and protect the eco-environment, it is important to grasp the eco-environmental situation of the disaster area in a rapid, accurate, and dynamic manner. With the aid of geographical information system (GIS), this paper extracts the key parameters of the eco-environment, and establishes an evaluation index system for ecoenvironment quality. On this basis, the eco-environment quality of the disaster area was evaluated based on the 2007-2017 Landsat remote sensing images, using the analytic network process (ANP). The results show that the eco-environment quality of the disaster area was improving, but the restoration process varied greatly around fault zone and on river banks, which should be the focal points of monitoring; the spatiotemporal difference in ecoenvironment restoration is mainly attributable to the development degree of secondary geological disasters, and indirectly caused by formation lithology; there was a huge gap between the restoration speeds of artificial restoration area and natural restoration area, but the gap narrowed over time. The research results provide the basis for scientific decision-making on eco-environment repair and restoration in places similar to the disaster area, promoting the green economy and living condition in those regions.
\end{abstract}

\section{INTRODUCTION}

The main sustainable development objective of the United Nations is to protect, restore, and promote sustainable use of terrestrial ecosystems, perform sustainable forest management, combat desertification, prevent and reverse land degradation, and curb the loss of biodiversity. According to the World Risk Report, "Human development has greatly increased the potential risks, which requires a lot of scientific research for humans to understand the natural ecosystem, reduce risks and prevent various disasters." Earthquake is one of the most serious natural disasters. The ecological and environmental problems caused by earthquakes have become the main problems of many countries and regions. It's extremely urgent to deeply understand the destruction of the eco-environment caused by earthquakes and secondary geological disasters, as well as the restoration process of the eco-environment, and then propose the measures of eco-environment restoration in a targeted manner [1-3]. The quick and accurate extraction of information on key parameters of the eco-environment in the earthquake-stricken area is conductive to dynamically monitoring and scientifically evaluating the eco-environment restoration in this area, exploring the spatial distribution characteristics of the eco-environment, summarizing the effects and experience of ecological restoration and reconstruction after a strong earthquake, and implementing various ecological restoration measures. This is a scientific problem that needs to be solved urgently in the restoration of the eco-environment after the disaster, providing support for scientific decision-making on the restoration of the ecoenvironment in places similar to disaster area.

The 2008 Sichuan earthquake occurred on the central main fault Yingxiu-Beichuan of the Longmenshan fault zone. This region has important tributaries in the middle and upper reaches of the Yangtze River, such as the Jialing River, Minjiang River, and Dadu River, and a rich and diverse biological vertical zonation. As the main habitat of the national first-class protected animals such as giant pandas, golden monkeys, and takins, it's a water conservation area and an ecological service function protection area in China. It's also an important ecological barrier for Sichuan province and even the middle and upper reaches of the Yangtze River, with important ecological status [4-6]. After the earthquake, the secondary geological disasters in the disaster area entered an active period. Geological disasters such as landslides and mudslides will exist for a long time and form a disaster chain, which severely restricts the later restoration and reconstruction of the eco-environment [7-12]. Therefore, the ecoenvironment issues in the Sichuan earthquake-stricken area have long attracted continuous attention from domestic and foreign scholars. Wang et al. [3] assessed the impact of this earthquake on regional ecological services, and concluded that the soil system suffered the most, followed by carbon storage and water ecosystem service capacity; the interference of earthquake to the ecosystem service gradually weakened with the distance from the epicenter increasing. Through remote 
sensing data and field surveys, Ouyang et al. [13] evaluated the impact of earthquakes on ecosystems and found that earthquakes have a huge impact on water conservation, biodiversity protection, and natural cultural landscapes in the earthquake area. Cui et al. [14] found that the geological disasters of the earthquake caused the ecosystem degradation and vegetation destruction, making it a huge challenge to restore and reconstruct the vegetation. Based on remote sensing data, Yang et al. [15] extracted information parameters such as water and soil conservation, water conservation, and biodiversity protection etc. in the 10 disaster areas of the Sichuan earthquake, and evaluated the regional ecological restoration. Yunus et al. [16] proposed a new automatic quantitative evaluation algorithm VDA for the destruction of vegetation caused by new geological disasters of strong earthquakes, and the quantitative index VRR for the degree of post-earthquake vegetation restoration, thereby quantifying the impact of the Sichuan earthquake induced co-seismic and post-earthquake geological disasters on vegetation.

In recent years, scientists have realized that ecological restoration is an effective measure to improve fragile ecosystems and restrain geological disasters. Research on the coordination mechanism of eco-environment and geological disasters after earthquakes has been developed [17]. The litter layer has the function of filtering sediment and sponge. By retarding, filtering, and dispersing the surface runoff, it prevents the loss of soil particles, reduces the erosion intensity of the surface runoff, and prevents various surface erosion and gully erosion. Rainfall will first be reduced by $10 \%$ by the forest canopy, effectively preventing the surface soil from being eroded; the web-like root system consolidates the soil together, reinforces the slope and fixes the steep slope, greatly enhancing the soil's anti-corrosion strength. Ecological disaster prevention is beneficial [18]. Li et al. [19] studied the development of geological disasters and vegetation restoration after the Sichuan earthquake, and found that the area of geological disasters in the disaster area decreased at a rate of $12 \%$ per year, while the vegetation was restored at a rate of $15 \%-20 \%$ per year, indicating a good coupling between the development of geological disasters and vegetation restoration. Galve et al. [20] discovered that the implementation of structural protection measures on unstable slopes can reduce the risk of landslides in the short term, but it needs to be combined with the development of agriculture and forestry for the long-term effects. Yang et al. [21] concluded that the vegetation restoration in the damaged area of the Sichuan earthquake has a positive effect on preventing the occurrence of geological disasters, and disasters such as landslides will disappear within 20 years after the earthquake.

As above, the eco-environment in the disaster area of the strong earthquake has become the current research hotspot of ecology, environmental science, disaster science and other disciplines. In these researches, reliable research methods have been adopted, especially the wide application of $3 \mathrm{~S}$ technology in the research process, achieving certain research results. However, most of the researches focus on the surface attachments, geological environment, and geological disasters caused by earthquakes, but there is a lack of research on the dynamic changes of the eco-environment during each restoration period or between different periods. In view of the eco-environment characteristics in the disaster area and the existing problems in current research, this paper conducts a field survey and data analysis, and extracts the key information parameters for remotes sensing retrieval through the full use of $3 \mathrm{~S}$ technology. Then, based on the PSR framework model, an evaluation index system of the eco-environment was constructed to analyze the dynamics of the eco-environment in depth and realize the dynamic monitoring of the study area. This study shall provide theoretical basis for regional ecoenvironmental protection and scientific decision-making.

\section{MATERIALS AND METHODS}

\subsection{Study area}

Beichuan County is located in the northwestern part of Sichuan Province, with geographic coordinates of $103^{\circ} 44^{\prime} 42.41^{\prime \prime} \sim 104^{\circ} 43^{\prime} 15.37^{\prime \prime}$ east longitude and $31^{\circ} 33^{\prime} 35.63^{\prime \prime} \sim 32^{\circ} 13^{\prime} 10.97^{\prime \prime}$ north latitude, covering an area of $3083.30 \mathrm{~km}^{2}$. With high mountains and deep valleys, it has complex bottom lithology and geological structure, and intense tectonic movement. The Beichuan-Yingxiu fault in the Longmenshan fault zone has developed. Since the 1930s, 32 large earthquakes of magnitude 5 or more have occurred in the region, making it one of the areas with the strongest seismic activity and the highest frequency. The study area is an important water conservation area in the Chengdu Plain, and an important ecological barrier and biodiversity conservation area in China. The 2008 Sichuan earthquake and its secondary geological disasters caused a decline in the ecological carrying capacity, increased landscape fragmentation, threatened biodiversity, severely damaged the water resources, and degraded the ecological services of the study area.

\subsection{Data}

The paper mainly selected five phases of TM, ETM+ and OLI remote sensing data in 2007 (before the earthquake), 2008 (earthquake year), 2011 (early recovery), 2014 (mid recovery) and 2017 (mid and late recovery), and DEM data of 30m Resolution. The vegetation canopy water content and soil moisture were measured; data and information such as meteorology, land use, cultivated land quality, administrative boundaries, statistical yearbooks, and soil records in the study area were collected.

\subsection{The integrated methodology for eco-environment evaluation}

According to the characteristics of the post-earthquake ecoenvironment in the study area, an eco-environment evaluation index system was constructed based on the principles of the PSR model. This system consists of 8 pressure indices (soil erosion, ground slope, and land disturbance etc.), 10 state indices (ecological water content and vegetation coverage etc.), and 4 response indices (per capita GDP, and per capita income, etc.). Considering the mutual influence between the evaluation indices, the ANP method was selected to evaluate the ecoenvironmental quality [22-24]. The super matrix was used to calculate the weight of each index. Then, the eco-environment index of the study area was calculated in formula (1):

$$
W_{p}=\sum_{i=1}^{n} R_{i s} \times e_{i}
$$

where, $W_{p}$ is the comprehensive evaluation result value; $R_{i s} \mathrm{i}$ 
the standardized value of the $\mathrm{i}$-th index; $e_{i}$ is the weight value of the i-th index.
The technical route of eco-environment restoration evaluation in the study area is shown in Figure 1.

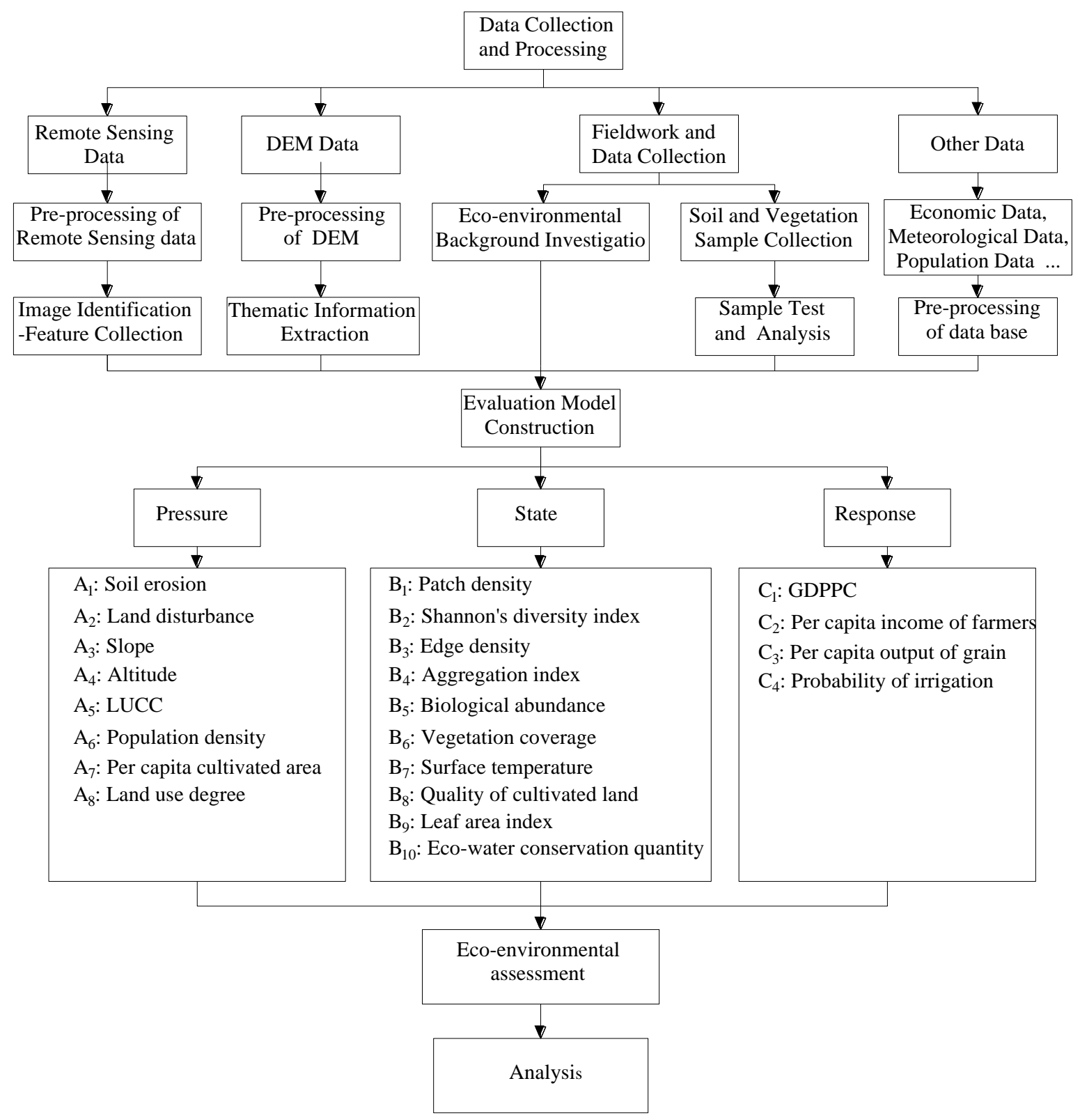

Figure 1. The framework for eco-environmental evaluation

Using Formula 2, algebraic operations were performed on the eco-environment of the study area at each time period to calculate the changes of eco-environment restoration.

$$
\Delta W_{p}=W_{p_{b}}-W_{p_{a}}
$$

where, $\Delta W_{p}$ is the number of changes in the eco-environment index in the two periods of $a$ and $b ; W_{p a}$ and $W_{p b}$ are the ecoenvironment indices in the periods $a$ and $b$ respectively.

\section{RESULTS AND ANALYSIS}

The ANP was applied to standardize the evaluation index [25]. The eco-environment quality index of the study area was calculated by formula 1 . This quality index is positively correlated with the eco-environment quality. Figure 2 shows the distribution of eco-environment quality in different periods.

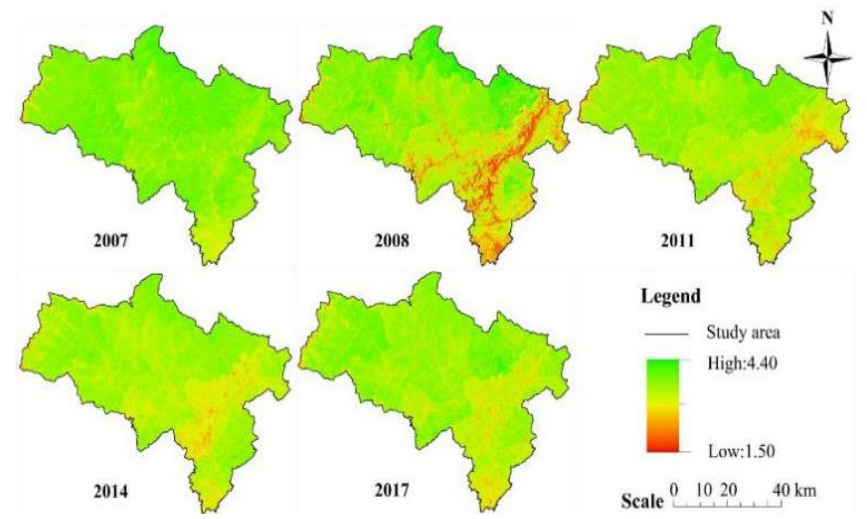

Figure 2. Eco-environment evaluation results in each period of the study area 


\subsection{Analysis for eco-environment changes in each period of the study area}

Using Formula 2, the changes of the eco-environment index based on the reference value was calculated, which was then divided into 7 levels according to the Technical Criterion for Eco-system Status Evaluation (HJ 192-2015). Table 1 lists the classification and statistical results of the eco-environment changes in each period of the study area.

Table 1. Statistics of changes in the eco-environment in each period of the study area

\begin{tabular}{cccccccc}
\hline Periods & $\begin{array}{c}\text { Significant } \\
\text { deterioration }\end{array}$ & $\begin{array}{c}\text { Obvious } \\
\text { deterioration }\end{array}$ & $\begin{array}{c}\text { Slight } \\
\text { deterioration }\end{array}$ & $\begin{array}{c}\text { Non- } \\
\text { change }\end{array}$ & $\begin{array}{c}\text { Slight } \\
\text { improvement }\end{array}$ & $\begin{array}{c}\text { Obvious } \\
\text { improvement }\end{array}$ & $\begin{array}{c}\text { Significant } \\
\text { improvement }\end{array}$ \\
\hline Before-after earthquake & $52.81 \%$ & $36.67 \%$ & $5.37 \%$ & $0.98 \%$ & $2.98 \%$ & $0.91 \%$ & $0.29 \%$ \\
The $1^{\text {st }}$ recovery period & $2.10 \%$ & $4.07 \%$ & $3.47 \%$ & $7.69 \%$ & $11.97 \%$ & $41.52 \%$ & $29.19 \%$ \\
The $2^{\text {nd }}$ recovery period & $1.23 \%$ & $8.37 \%$ & $22.76 \%$ & $26.91 \%$ & $15.07 \%$ & $16.64 \%$ & $9.02 \%$ \\
The $3^{\text {rd }}$ recovery period & $1.81 \%$ & $9.50 \%$ & $7.05 \%$ & $48.67 \%$ & $15.82 \%$ & $15.12 \%$ & $2.03 \%$ \\
\hline
\end{tabular}

It can be seen from Table 1 above that the eco-environment of the study area has changed significantly after the earthquake; the eco-environment with significant deterioration and obvious deterioration, accounted for $52.81 \%$ and $36.67 \%$ of the total area respectively, which dominated in the entire study area; the area with the eco-environment improved to varying degrees only accounted for $4.18 \%$, which contributed less to the improvement of the eco-environment. From 2008 to 2011, some areas' eco-environment improved obviously, accounted for $41.52 \%$, followed by areas improved significantly, and the two jointly led the continuous improvement of the ecoenvironment in the entire study area. From 2011 to 2014, the number of non-change areas increased significantly, accounting for $26.91 \%$ of the total area. The overall ecoenvironment of the study area tended to be better, but the areas with slight deterioration increased significantly, reaching $22.76 \%$. In 2014-2017, non-change areas became dominant, accounting for $48.67 \%$ of the total; the slightly improved and significantly improved areas mainly affect the development direction of the entire region's eco-environment. During the entire study period, the eco-environment has developed from significant deterioration to continuous improvement, indicating that various ecological restoration measures have played a positive role and the entire ecosystem has developed soundly.

\subsection{Analysis for eco-environment changes in different formation lithology areas}

The main rock types in the study area include siliceous rock, carbonate rock, phyllite, phyllite-slate, sandstone, and sand shale, etc. Based on the Standard for Engineering Classification of Rock Mass (GB/T 50218-2014), they were classified into hard rock group, harder rock group, softer rock group, soft rock group and extremely soft rock group. In terms of different rock groups, the changes in the eco-environment in 5 periods of the study area were studied, the ecoenvironment improvement speed of each engineering geological rock group was calculated, as shown in Figure 3.

It can be seen from Figure 3 above that the eco-environment conditions of different lithological areas were quite different before the earthquake, but tended to deteriorate as the lithological hardness decreases. After the earthquake, the soft rock, softer rock, and extremely soft rock areas were most affected, with the average ecological index dropping to 2.64 , 2.76 , and 2.70 respectively, while the hard rock area was the least affected, with the average ecological index dropping only 0.29. In 2008-2011, the eco-environment of each lithology area improved to varying degrees. The soft rock area improved the fastest, with an increase of 0.67 , followed by extremely soft rock and softer rock increasing by 0.52 and 0.40 , respectively, while the eco-environment of hard rock and harder rock areas was restored at a relatively slow rate. In 2011-2014, the restoration of the regional eco-environment slowed down significantly. The extremely soft rock and harder rock areas improved the most, while the eco-environment of hard rock areas deteriorated slightly. In 2014-2017, the ecoenvironment of the extremely soft rock area became worse than in the previous period, while the rest areas slightly improved. Thus, there are big differences in the impact intensity of the earthquake on eco-environment in different lithological areas and the speed of later recovery. The formation lithology has a greater impact on the restoration of the eco-environment.

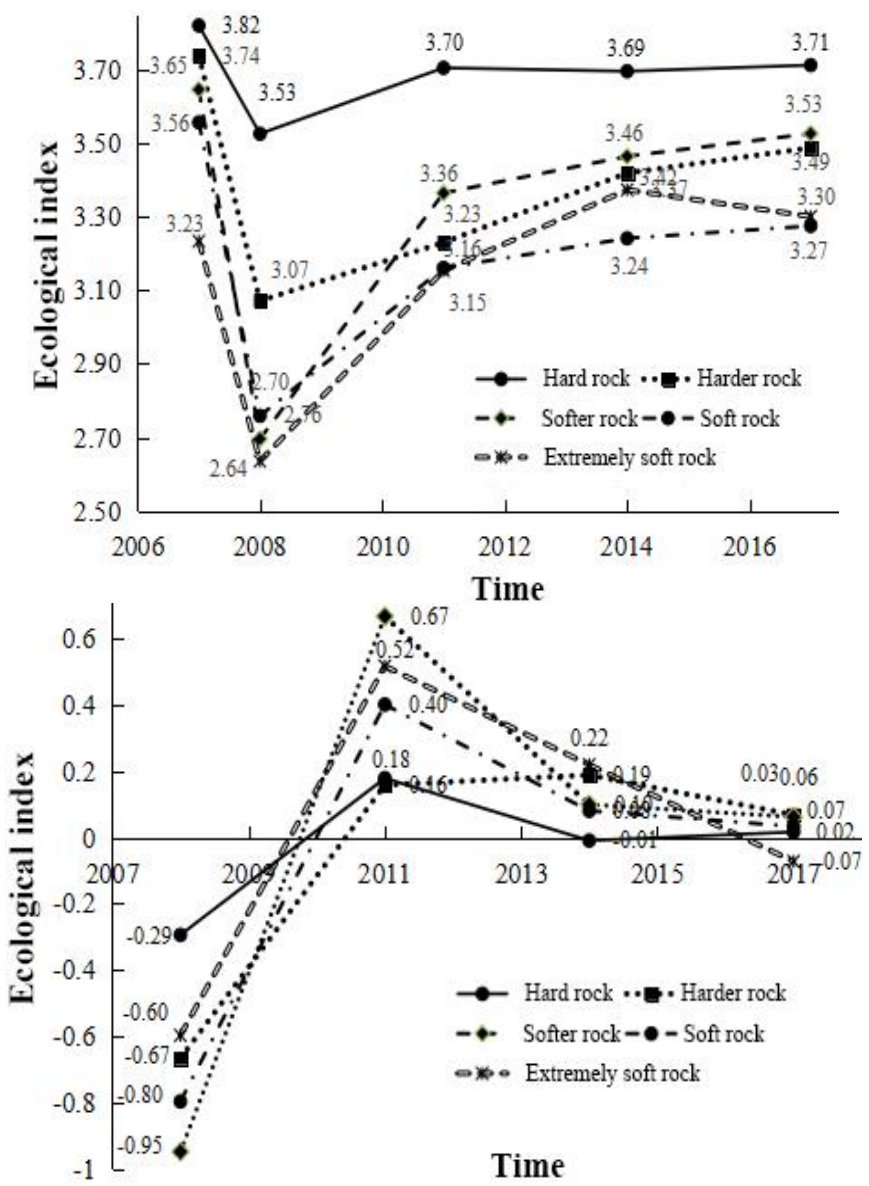

Figure 3. Changes in the average ecological index and improvement speed in different formation lithology areas 


\subsection{Analysis for eco-environment changes in different secondary geological disaster areas}

The development of secondary geological disasters in the disaster areas of the 2008 Sichuan earthquake has the characteristics of wide range, large number, high density, and strong destructive power. The secondary geological disasters in the study area show obvious zonal distribution, which are consistent with the strike of the Yingxiu-Beichuan earthquake fault zone, i.e., the closer to the fault zone, the higher the disaster development degree. The changes in the ecoenvironment of different secondary geological disaster areas in 5 periods were studied, and the improvement speed of ecoenvironment index in each region was calculated, as shown in Figure 4.
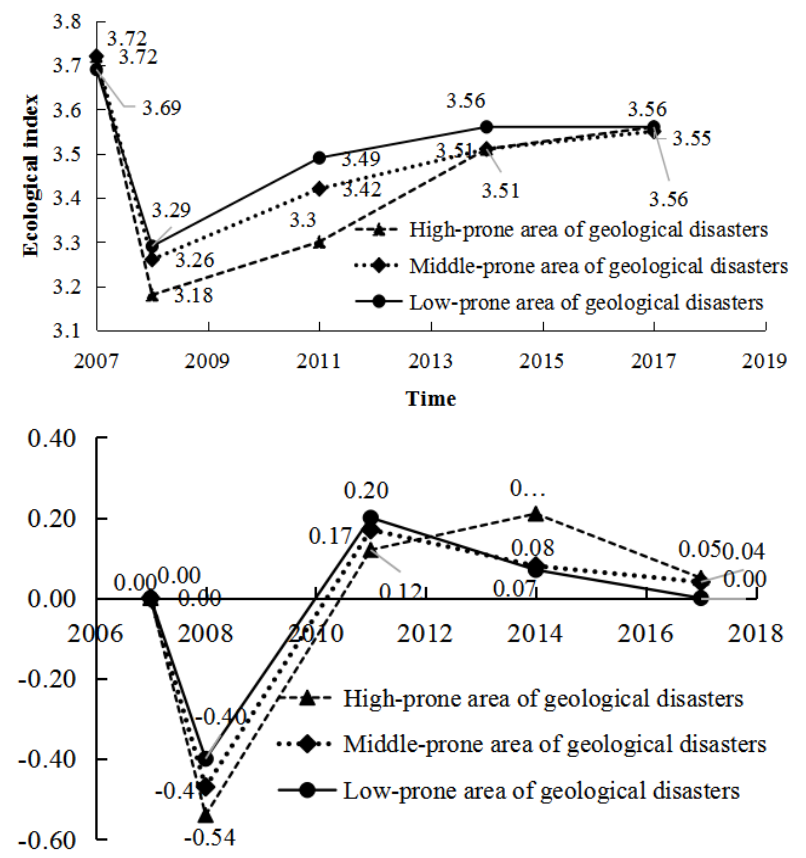

Figure 4. Changes in the average ecological index in different areas and the improvement speed

It can be seen from Figure 4 that the eco-environment indices of the three areas before the earthquake were very close, while the eco-environment conditions after the earthquake were basically proportional to the development degree of geological disasters; geological disasters caused the regional eco-environment index to drop by an average of 0.47 , and the average ecological index in the geological disasterfrequent areas dropped the most, from 3.72 in 2007 to 3.18 . After 3 years of restoration, the regional eco-environment improved rapidly, and the regional eco-environment in the more prone areas of the geological disaster recovered the fastest, with the average ecological index up to 3.49 , while the ecological index of the frequent and prone areas has also increased by 0.12 and 0.17 respectively. From 2011 to 2014 , the improvement of the eco-environment in the three areas slowed down significantly. The average ecological index recovered to $3.56,3.51$ and 3.51 respectively, and that of the frequent areas was consistent with the prone areas. In 20142017, the improvement speed of the eco-environment in the three areas further slowed down, but the average ecological index was closer, to be $3.56,3.56$, and 3.55 respectively, indicating that the stability of the entire ecosystem is further enhanced. From this, the development degree of secondary geological disasters is a key factor in the changes of the ecoenvironment. It's is directly proportional to the ecoenvironment.

\subsection{Analysis for eco-environment changes under different restoration measures}

Due to differences in the degree of damage to the ecoenvironment, geographic location, engineering difficulty, and suitability of restoration measures, ecological restoration measures also vary, affecting the restoration process of the eco-environment. In the recent years after 2008 Sichuan earthquake, the differences in the restored eco-environment under different restoration measures have been revealed. Through on-site investigation, data analysis, and remote sensing images, 42 representative areas with greater damage in the earthquake were selected, including 16 artificial restoration areas and 26 natural restoration areas. The changes in the ecological index of the study area are shown in Figure 5 .
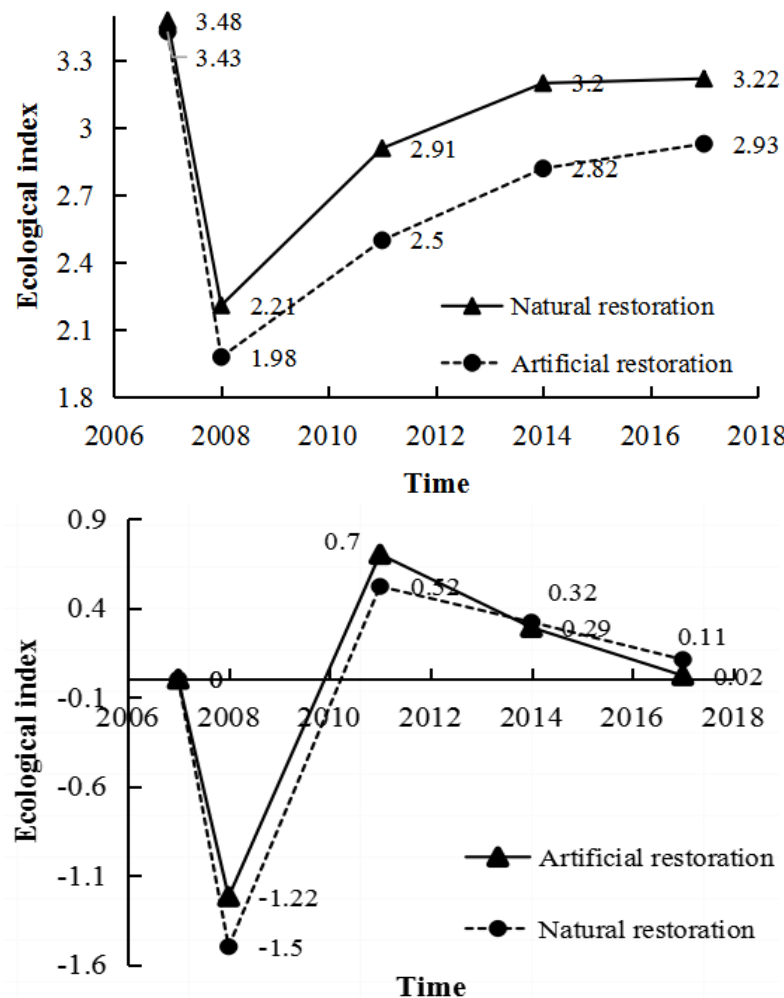

Figure 5. Changes in the average ecological index and the improvement speed

The average ecological index of 42 typical areas before the earthquake was between 3.12 and 3.79, indicating a generally good eco-environment. After the Sichuan earthquake in 2008, the eco-environment of 41 areas deteriorated significantly, and one area was obviously deteriorated; the average ecological index of artificial restoration areas dropped to 2.21, and that of natural restoration areas dropped to 1.98 . In 2008-2011, the average ecological index of 16 artificial restoration areas rose to 2.91 , and that of 26 natural restoration areas increased to 2.50 , indicating that the ecological restoration speed of artificial restoration areas was significantly higher than that of natural restoration areas. In 2011-2014, the average ecological index of artificial restoration areas rose to 3.20 , and that of natural restoration areas to 2.82 . During this period, the 
improvement of the eco-environment slowed down as a whole, but the eco-environment in some natural restoration areas improved at a higher rate than that of artificial restoration areas. In 2014-2017, the average ecological index of the artificial restoration area rose to 3.22 , and that of the natural restoration area increased to 2.93; the restoration speed of ecoenvironment in the natural restoration area further exceeded that of the artificial restoration area, and the ecological function of the artificial restoration area gradually tended to stable.

\section{CONCLUSIONS}

(1) Earthquakes and their secondary geological disasters do great damages to the eco-environment. The disaster chain formed by them also severely restricts the eco-environment restoration. Due to frequent geological disasters, large terrain slopes and continuous human activities, the Beichuan Great Fault Zone and the river banks vary significantly in the recovery process of eco-environment, to be used as key areas for dynamic monitoring and evaluation in this study. From 2007 to 2017, the regional eco-environment developed from a significant deterioration to a continuous improvement, and various ecological restoration measures played a positive role in the health development of the entire ecosystem. Meanwhile, the non-change areas in the study area recovered from $0.98 \%$ in the earthquake year to $48.67 \%$ in 2017 , indicating that the ecosystem's anti-interference ability and stability have increased; the eco-environment in some areas deteriorated, mainly because the ecology of the area after the earthquake is fragile, and secondary geological disasters are prone to occur under external interference.

(2) Eco-environmental problems in extremely soft rock, soft rock and softer rock areas are more prominent under earthquake. Lithology determines the weathering rate, soil formation efficiency and soil composition, affects the distribution of water resources and the growth rate of vegetation, and further influences the restoration rate of the eco-environment. The area with higher lithological strength has stronger anti-interference ability, but it is more difficult to weather and form soil layer, and water conservation ability is also worse. Once the eco-environment is destroyed, it is difficult to recover, resulting in the increase in the ecological restoration speed of the extremely soft rock, soft rock and softer rock in the later ecological restoration process, and a decline in the ecological restoration speed of hard rock and harder rock areas. Therefore, the formation lithology affects the distribution of geological disasters and the pedogenic process, resulting in differences in the restoration of the ecoenvironment.

(3) The development of geological disasters affects the growth of vegetation and land use. As the vegetation coverage increases, the buffering effect on rainfall increases, and the roots of the vegetation also have a reinforcing effect on the loose soil layer and play a role in slopes and well protect the slope, thereby reducing the development intensity of geological disasters. The development degree of secondary geological disasters is a key factor in the restoration of the ecoenvironment. The development degree of secondary geological disasters is directly proportional to the overall ecoenvironment, forming a mutual feedback mechanism. Therefore, the key to post-disaster ecological restoration is to eliminate the hidden dangers of geological disasters to the greatest extent, make full use of the favorable factors after the geological disasters, and speed up ecological restoration.

(4) The artificial restoration area and the natural restoration area both use active restoration measures for the damaged ecoenvironment, but there is still a huge gap in the restoration of the eco-environment. The most critical role of artificial restoration is to quickly reduce or even eliminate hidden dangers of secondary geological disasters, and to provide protection for the growth and development of vegetation. At the same time, the huge root system of vegetation not only has a significant solidification effect on the soil, but also reduces the erosion of the ground surface by precipitation and inhibits the occurrence of geological disasters. Therefore, the ecoenvironment of the artificial restoration area can be quickly restored to a higher level. In the natural restoration area, the eco-environment has a longer restoration cycle, and greater sustainability, to further narrow the gap from the natural restoration area. For this, the earthquake-stricken areas should focus on natural restoration, supplemented by artificial restoration, and give full play to natural self-recovery capabilities.

\section{ACKNOWLEDGMENT}

This work is supported by Sichuan Science and Technology program (Grant No.: 20ZDYFS0308)

\section{REFERENCES}

[1] Yang, X., Zhang, Q. (2013). Seismic spatial information grid: applications of geo-informatics in earthquake disaster management. In International Conference on Geo-Informatics in Resource Management and Sustainable Ecosystem, pp. 397-406. https://doi.org/10.1007/978-3-642-41908-9 41

[2] Chen, L., Wu, F., Yang, W., Zhang, J. (2012). A comparison on ecosystem services before/after " 5.12 " Wenchuan earthquake. Acta Ecologica Sinica, 32(5): 271-273. https://doi.org/10.1016/j.chnaes.2012.07.002

[3] Wang, Y.K., Fu, B., Xu, P. (2012). Evaluation the impact of earthquake on ecosystem services. Procedia Environmental Sciences, 13: 954-966. https://doi.org/10.1016/j.proenv.2012.01.089

[4] Opdam, P., Foppen, R., Vos, C. (2001). Bridging the gap between ecology and spatial planning in landscape ecology. Landscape Ecology, 16(8): 767-779. https://doi.org/10.1023/A:1014475908949

[5] Loucks, C.J., Zhi, L., Dinerstein, E., Dajun, W., Dali, F., Hao, W. (2003). The giant pandas of the Qinling Mountains, China: a case study in designing conservation landscapes for elevational migrants. Conservation Biology, 17(2): 558-565. https://doi.org/10.1046/j.15231739.2003.01494.x

[6] Zhang, J., Hull, V., Huang, J., Yang, W., Zhou, S., Xu, W., Huang, Y., Ouyang, Z.Y., Zhang, H.M., Liu, J. (2014). Natural recovery and restoration in giant panda habitat after the Wenchuan earthquake. Forest Ecology and Management, 319: 1-9. https://doi.org/10.1016/j.foreco.2014.01.029

[7] Cui, P., Wei, F., Chen, X., He, S. (2008). Geo-hazards in Wenchuan earthquake area and countermeasures for disaster reduction. Bull Chin Acad Sci, 23(4): 317-323. 
[8] Zhang, S., Zhang, L.M. (2017). Impact of the 2008 Wenchuan earthquake in China on subsequent long-term debris flow activities in the epicentral area. Geomorphology, 276: 86-103. https://doi.org/10.1016/j.geomorph.2016.10.009

[9] Fan, X., Juang, C.H., Wasowski, J., Huang, R., Xu, Q., Scaringi, G., van Westen, C.J., Havenith, H.B. (2018). What we have learned from the 2008 Wenchuan Earthquake and its aftermath: A decade of research and challenges. Engineering Geology, 241: 25-32. https://doi.org/10.1016/j.enggeo.2018.05.004

[10] Fan, R.L., Zhang, L.M., Wang, H.J., Fan, X.M. (2018). Evolution of debris flow activities in Gaojiagou Ravine during 2008-2016 after the Wenchuan earthquake. Engineering Geology, 235: 1-10. https://doi.org/10.1016/j.enggeo.2018.01.017

[11] Fan, X., Scaringi, G., Korup, O., West, A.J., van Westen, C.J., Tanyas, H., Hovius, N., Hales, T.C., Jibson, R.W., Allstadt, K.E., Zhang, L.M., Evans, S.G., Xu, C., Li, G., Pei, X.J., Xu, Q., Huang, R.Q. (2019). Earthquakeinduced chains of geologic hazards: Patterns, mechanisms, and impacts. Reviews of Geophysics, 57(2): 421-503. https://doi.org/10.1029/2018RG000626

[12] Chen, M., Tang, C., Xiong, J., Shi, Q.Y., Li, N., Gong, L.F., Wang, X.D., Tie, Y. (2020). The long-term evolution of landslide activity near the epicentral area of the 2008 Wenchuan earthquake in China. Geomorphology, 367: 107317 https://doi.org/10.1016/j.geomorph.2020.107317

[13] Ouyang, Z.Y., Xu, W.H., Wang, X.Z., Wang, W.J., Dong, R.C., Zheng, H., Li, D.H., Li, Z.Q., Zhang, H.F., Zhuang, C.W. (2008). Impact assessment of Wenchuan Earthquake on ecosystems. Acta Ecologica Sinica, 28(12): 5801-5809.

[14] Cui, P., Lin, Y.M., Chen, C. (2012). Destruction of vegetation due to geo-hazards and its environmental impacts in the Wenchuan earthquake areas. Ecological Engineering, 44: 61-69. https://doi.org/10.1016/j.ecoleng.2012.03.012

[15] Yang, M., Xie, Q., Fang, Z.L., Liu, X.F., Liao, W.Y., Wang, P. (2016). Assessment of "5.12" Wenchuan earthquake restoration: Ecological services function in severely afflicted areas. Resources and Environment in the Yangtze Basin, 25(4): 685-694. https://doi.org/10.11870/cjlyzyyhj201604020

[16] Yunus, A.P., Fan, X., Tang, X., Jie, D., Xu, Q., Huang, R. (2020). Decadal vegetation succession from MODIS reveals the spatio-temporal evolution of post-seismic landsliding after the 2008 Wenchuan earthquake. Remote Sensing of Environment, 236: 111476. https://doi.org/10.1016/j.rse.2019.111476

[17] Shen, P., Zhang, L.M., Fan, R.L., Zhu, H., Zhang, S. (2020). Declining geohazard activity with vegetation recovery during first ten years after the 2008 Wenchuan earthquake. Geomorphology, 352: 106989. https://doi.org/10.1016/j.geomorph.2019.106989

[18] Sestras, P., Bondrea, M.V., Cetean, H., Sălăgean, T., Bilaşco, Ş., Naş, S., Spalevic, V., Fountas, S., Cimpeanu, S.M. (2018). Ameliorative, ecological and landscape roles of Făget Forest, Cluj-Napoca, Romania, and possibilities of avoiding risks based on GIS landslide susceptibility map. Notulae Botanicae Horti Agrobotanici Cluj-Napoca, 46(1): 292-300. https://doi.org/10.15835/nbha46110866

[19] Li, Z., Jiao, Q., Liu, L., Tang, H., Liu, T. (2014). Monitoring geologic hazards and vegetation recovery in the Wenchuan earthquake region using aerial photography. ISPRS International Journal of GeoInformation, 3(1): 368-390. https://doi.org/10.3390/ijgi3010368

[20] Galve, J.P., Cevasco, A., Brandolini, P., Soldati, M. (2015). Assessment of shallow landslide risk mitigation measures based on land use planning through probabilistic modelling. Landslides, 12(1): 101-114. https://doi.org/10.1007/s10346-014-0478-9

[21] Yang, W., Qi, W., Zhou, J. (2018). Decreased postseismic landslides linked to vegetation recovery after the 2008 Wenchuan earthquake. Ecological Indicators, 89: 438-444. https://doi.org/10.1016/j.ecolind.2017.12.006

[22] Saaty, T.L. (1996). Decision making for Leaders. Pittsburgh: RWS Publications.

[23] Chemweno, P., Pintelon, L., Van Horenbeek, A., Muchiri, P. (2015). Development of a risk assessment selection methodology for asset maintenance decision making: An analytic network process (ANP) approach. International Journal of Production Economics, 170: 663-676. https://doi.org/10.1016/j.ijpe.2015.03.017

[24] Zhou, L., Yang, J.P. (2011). Risk assessment based on fuzzy network (F-ANP) in new campus construction project. Systems Engineering Procedia, 1: 162-168. https://doi.org/10.1016/j.sepro.2011.08.027

[25] Szlafsztein, C., Sterr, H. (2007). A GIS-based vulnerability assessment of coastal natural hazards, state of Pará, Brazil. Journal of Coastal Conservation, 11(1): 53-66. https://doi.org/10.1007/s11852-007-0003-6 